\title{
REAL LIFE LEARNING: THE CHALLENGE OF CREATING AND ESTABLISHING THE ROLE OF ONLINE AND VIRTUAL LEARNING ENVIRONMENTS FOR ALL
}

Focus Group - 3

Anton Knierzinger (Austria, chair), Marijke Hezemans (Netherlands, rapporteur), Paul Nicholson (Australia, rapporteur), Joberto Martins (Brazil), Ricardo Azambuja Silveira (Brazil)

Key words: Virtual learning environment, online learning, real-life learning.

\section{PROBLEM SITUATION}

In discussing the focus question in an international group of educational professionals, we concluded that the critical element in creating and establishing the role of online and virtual learning environments is the teacher rather then the virtual learning environment itself. We adopted the perspective of seeing the virtual learning environment as a tool; its effectiveness in the learning process depends on the way it is used. So ICT (the virtual learning environment) is like a football. For an exciting match we need to train the football players rather then enhancing or redesigning the football that is being used.

\section{They need to know how to play the game!}

Therefore our problem definition reads:

- Teachers need a minimum level of ICT-competence, and 

rapporteur), Paul Nicholson (Australia, rapporteur), Joberto Martins (Brazil), Ricardo Azambuja Silveira (Brazil)

- Need to be exposed to a range of different kinds of multi-media, distance-learning methods and other 'ICT-tools' commonly found in educational settings, and

- Need to change their culture to become learners too.

- But first and for all: they should develop expertise in the selection and use of a range of different pedagogical models.

\subsection{The Football Player}

\section{If you have a new shining football, you want to master nice tricks with it ...}

The introduction of new types of media - streaming videos, hypervideos, and video-based E-Lectures - into classrooms was addressed in a nationwide Austrian school project in which a large number of digitized audiovisual media were developed. The aim of the project was to create an Internet-based platform which allows teachers to access a large database of digitized educational movies, equip it with convenient tools for searching, ordering and downloading, and gain some empirical insights in its acceptance by teachers and students, its feasibility for classroom teaching, and its appropriate instructional scenarios.

After its components had been designed, implemented, and tested, the AVS media was made available via the World Wide Web, and all Austrian schools were given the opportunity to participate in a field trial. Overall, 89 schools decided to take part in the field trial, which lasted over one year and was free of charge. After resolving most of the technical problems during the first few months, the teachers were encouraged to try out these new possibilities in their classroom.

One of the findings in this project was that AVS media led the participants to change their teaching strategies. The majority $(54 \%)$ reported an increase in their usage of audiovisual media in the classroom lessons. But media use did not only change in quantity, but also in quality, ranging from "chalk and talk" modes to learning projects and group work.

Thus, in sum, the strategy of providing such material in a digitized and easy-to-access manner seems to be a promising contribution of new media in the endeavour of introducing more enriched and varied teaching styles at school. 


\subsection{The Football Trainer}

\section{The use of new materials creates a faster game - players need to be trained in new tactics...}

Dutch universities of professional education are working in co-operation with institutions in the field to develop and implement programmes which are intended to give students optimum preparation for the reality and dynamics of professional practice. These new programmes aim to provide learning environments which enable students to develop into starting professionals: they develop their competence and professional expertise in learning environments of varying complexity.

This short case description shows how a tutor, supported by ICT, can realise a personal learning process in such a way as to effectively guide and supervise an analogous learning process for the student. In this case the tutor and the student are central; the professional field provides the (ICT) tools for practising this competence management. The case description is taken from the project 'Competence development \& portfolio': a project which was carried out in the part-time Economics programmes at the Utrecht University of Professional Education (Hogeschool van Utrecht). The project aims to maximise the part-time students' competence development (learning) with the help of a digital learning environment (e-folio environment) developed by tutors who are coached by two educational staff members attached to the project.

In this learning environment part-time students learn among other things to reflect on their work experience by means of a personal development plan and the competence profile of the programme. As well as self-reflection, which on the student's initiative is coached by the tutor, reflection also takes place in peer groups. The project aims to produce an instrument, a digital learning environment including portfolio functions, which supports and/or makes visible competence development on the basis of a personal development plan. Accompanying assignments, and a tutoring and assessment protocol are also developed, so that coaching and assessment are related to the competence profile of the programme.

Analogous to the part-time students' learning process, a programme was set up within the project in co-operation with the Virtual Learning Centre (VLC) of the Utrecht University of Professional Education to support the tutors' competence development in the e-folio environment. The aim of the course is two-fold:

- To train competent e-folio tutors, both in relation to guiding the students' development as well as ICT-skills; and 

rapporteur), Paul Nicholson (Australia, rapporteur), Joberto Martins (Brazil), Ricardo Azambuja Silveira (Brazil)

- To act as an example to students and colleagues.

Starting from their personal learning needs (personal competence profile), the e-folio tutors each made a personal development plan. The development plan shows the way in which the above competencies will be developed (learning activities) and which forms of support (e.g. training or peer assisted learning) are needed. The tutors collect their evidence in their digital portfolio (e-folio) by means of which they can demonstrate that they have completed learning activities and thus have developed the above competencies. The course is rounded off with a portfolio assessment. In the portfolio assessment two assessors independently assess the evidence presented in relation to the competence profile of an 'e-folio tutor'.

The preceding has shown how tutors as professionals can give form to their own learning process supported by ICT: they create a portfolio and make a personal development plan. In the process of tutoring, students use the same tools; they too after all are being trained as starting professionals. Through guiding students by means of the same sort of learning assignments as they themselves are carrying out, tutors can act as role models; they show students how they themselves learn as professionals and use ICT-tools.

\section{CONCLUSIONS}

The 'real-life focus for creating and establishing the role of online and virtual learning environments 'for all' is strongly dependant on people. This means that:

- The people involved, in particular, teachers, should have (or be supplied with) a minimum set of 'pedagogical abilities' in order to promote a successful project/learning initiative.

- In overall strategic terms it is also agreed that people and resources (technology, services, platforms etc.) should be coupled and integrated in an effective case-by-case basis.

\section{REMAINING QUESTIONS: TOPICS FOR FURTHER RESEARCH}

- How can ICT support 'real-life' learning? (How many teachers were exposed to a virtual learning environment as students? If not, are teachers disadvantaged?) 
- Who's 'real-life' is it?

- What is so good about real-life learning? ('real-life' learning vs. 'school'-learning)

- What are the attributes of real-life learning?

- When is 'virtual' real? (When is it perceived as real by stake holders?)

\subsection{The Football}

\section{Enhancing the quality of the ball enables smooth playing.}

In our focus group discussions we wondered about what the attributes are of a good (virtual) learning environment. We asked the conference attendants for suggestions. They came up with the following ones:

- adaptable, multi functional

- personalized

- flexible

- find a customer who pays for it! + return of invest

- acknowledges and utilises earlier research + development work on screen design and educational computing, doesn't re-invent bad wheels

- supporting collaboration and joint knowledge creation (within)

- minimize technical problems

- reliable (works all the time!)

- functionality that is really needed / helpful to user

- friendly interface

- good useability

- easy to use

- portfolios

- virtual lab prototype

- receptive mind

- contextualised

- authenticity

- authentic complex challenging

Although most of us try to address the suggestions mentioned above in our ongoing projects, we think that here also questions remain. So further research in more technical aspects is needed as well. 